in the copper and copper alloy and aluminium industries, and the efficiency of different types of cleaning plant. Corrosion studies continued to occupy a large place in the Association's programme, and, besides development of a thermo-electric gauge for the non-destructive measurement of the thickness of metal coatings, creep-resisting alloys have been developed, including thorium alloys for possible nuclear fuels, titanium alloys for gas-turbine compressor blocking and zirconium alloys for constructional purposes in nuclear plant. Potentiometer studies by the Research Association of British Paint, Colour and Varnish Manufacturers have advanced knowledge of the influence of many anti-corrosive pigments on the electro-chemistry of corrosion processes, and, together with radio-chemical and autoradiographic techniques, have gone far to show how red lead pigment in paint behaves on steel and nonferrous metals. Studies on materials for the protection of metal-sprayed steel have indicated the value of etch primer pre-treatments and of paint media which do not react with the sprayed metals, and have influenced the choice of treatments designed for the Forth and Tamar road bridges. The development of testing methods to indicate the firing propensity of the class of organic pigments known as toners when treated with resinous materials to enhance colour quality and investigations of the effect of various kinds of resin used have led to a marked decrease of such fires.

The Production Engineering Research Association has developed an improved design of reamer which is estimated to increase production-rates by $2-5$ times in most industrial applications and the reamer life 3-8 times. New approaches are being made to the design of structures, and the principles evolved are being increasingly applied by machine-tool makers in the design and manufacture of new machines, while a detailed metallographic study of the mechanism of shear during hole-punching operations has resulted in a new technique for producing precision punched holes in sheet or strip materials, known as finish piercing. A new model of automatic springcoiling machine being developed by the Spring Manufacturers' Research Association is expected to capture a large part of the export market. The results of investigations of the effect of non-metallic coatings on the corrosion-fatigue strength of springs which have shown that several resinous and plastic coatings possess good adhesion, abrasion resistance and mechanical strength, as well as withstanding corrosion-fatigue conditions for more than $50 \times 10^{6}$ stress reversals are being applied in the industry to protect finished springs against corrosion.

\title{
THE MEDICAL RESEARCH COUNCIL
}

$\mathrm{B}$ ESIDES accounts of the work of its own research units and that of institutions which it assists with finance, the annual report of the Medical Research Council is of interest to all men of science for the lucidity of a series of articles which have been selected to illustrate some aspects of the Council's work*. Among them are the physiological exploration of physical symptoms of mental and cerebral illness; mental disorders in old age; replacement therapy in hæmophilia and Christmas disease; trachoma and inclusion blennorrhcea; the early lesion of dental caries; the bacterial cell wall and the anthropological significance of blood groups.

Of outstanding value, however, is an important article describing the modern role of a research council in encouraging medical and biological research.

It is now fifty years since, with the creation of the former Medical Research Committee, Great Britain took the lead in setting up central organizations for research. During this period, society, in common with those of other developed countries, has changed profoundly. Fifty years ago appreciation of the part that research would come to play in the machinery of Government was confined to a few far-sighted men. Now it is taken for granted, and the question of how most effectively to organize support for research and development has become a matter of continuing concern to all modern Governments.

In the course of its development a central organizaation for research passes through a series of stages.

At the outset it is conceived of as a means of satisfying certain special needs which cannot be or are not being met by existing agencies for research-universities on one hand and the practising profession or industry on the other.

* Committee of Privy Council for Medical Research. Report of the Medical Research Council for the year 1960-1961. Pp. vifi +372 . (Cmnd. 1783.) (London: H.M.S.O. 1962.) 21s, net.
It is soon found, however, that these ad hoc requirements cannot always be met on the basis of existing knowledge, nor can reliance be placed on the chance that the interests of others will incidentally produce what is required. The second stage is then entered, when such organizations are driven to employ their own staff and find themselves increasingly involved in 'basic' research to fill gaps in knowledge that they have identified. In Great Britain, this stage was reached before the end of the First World War.

The next stage comes with the recognition that it is impossible for any organization to foresee its needs for more than a few steps ahead; that it is no more than enlightened self-interest to support any research that promises additions to knowledge even though its practical utilization cannot immediately be foreseen. In the 1930's, for example, it was impossible to foresee the atom bomb and, consequently, the hazards to health that might follow its use. Had not the Medical Research Council supported as subjects for study, in their own right, research into the effects of ionizing radiations on cells and on the production of mutations, they would not have been in a position, twenty-five years later, to give an assessment to the Government of the effects of fall-out or the hazards of such radiation. Again, looking to the future, the problem of 'population pressures' is looming ahead. Necessarily such a problem cannot be approached. directly, and only partially by retrospective observavation on human populations. It is evident, however, that if informed judgements are to be made, every fragment of knowledge from ecology, ethology, nutrition and genetics may be required.

The Medical Research Council conceives its function as: to watch over the whole fields of medical and related biological research so as to foresee, to the best of its ability, the needs and opportunities; to give support to any promising research in these fields irrespective of the agent concerned; to work in 
partnership with the universities and professions on one hand and the various Government departments on the other, so that new knowledge may be made available as the need arises.

It is according to this concept that the Council has devised its organization and formulated principles of working. These developments in the concept of the function of a central research organization are set out for two reasons. The first is that it is not yet fully realized that, nowadays, such organizations cannot remain pre-occupied with the institutions and staff for which they are directly responsible, but must pay attention to the development of knowledge as a whole in the field with which they are concerned. The second is that, when viewed in this larger perspective, many of the detailed problems of management disappear.

At the level of management the task of a research council is to reconcile two apparently conflicting requirements. On one hand, it has to try to ensure that the new knowledge required by society through Government is forthcoming and to this end has to distribute its support of research according to its assessment of present and future needs. On the other hand, it has so to devise its conditions of support as to preserve to individual workers that intellectual initiative without which creative work cannot develop. The problem for a research organization is thus to reconcile the implementation of a balanced and comprehensive research policy at the national level with the need for intellectual freedom at the level of the individual or the research team.

The solution of this dilemma is largely a matter of the scale of operation. If resources are restricted, or one thinks only in terms of individual institutions or particular organizations, the dilemma is real, and, in order to discharge its social obligations, a research organization may then be forced to have recourse to control and direction, even at the risk of inhibiting its workers in the creative thought and initiative on which its efficiency ultimately depends. But if the scale of operation is adequate the difficulty need not arise; for if support has been spread widely and with foresight, and if the central organization commands the confidence of scientists in general, then the relevant spontaneous interest can practically always be found. In other words, the solution of the dilemma lies in drawing a distinction between direction of research policy and directing individuals. It is of the essence of policy to have an object; but in relation to creative work the path to that object lies not through prescription to individuals, but through the informed selection of projects to be supported.

The question of what is adequate scale of operation for a central research organization with comprehensive social obligations in its particular field is, therefore, of critical importance. To-day the answer can no longer be in doubt. The demand for new knowledge is such that nothing less than the national scale will suffice, for it is only on this scale that the requisite variety of research work, interests and institutions can be found to allow the necessary freedom of initiative in policy.

There are only two qualitatively different types of scientific investigation: that which is directed to increasing understanding of naturally occurring phenomena-research-and that which aims at bringing knowledge so gained to the solution of human needs - applied research or development. Even these are little more than abstractions at either extreme of the range. Between them lie every shade and combination of activity, and it is this that makes organization in science possible. No research worker is entirely divorced in interest from his fellows or indifferent either to the use that can be made of his work or to its theoretical implications. All range, to some extent, about the centre-point of their interests, provided that they are not prevented by segregation from habitual contact with workers whose interests are contiguous. It is a major task of organization to promote such interplay. Blood transfusion would be hamstrung if separated from relevant investigations in genetics or immunopathology. Research in endocrinology would be grossly handicapped but for the experience available in clinical practice. Laboratory and practical work in nutrition mutually interact. The interdependence of chemistry, biochemistry, chemical pathology and the study of human metabolic diseases is evident. There is a regrouping of disciplines, a prominent feature of which is the disappearance of the previous barriers between the laboratory and practice. It would be undesirable, on either theoretical or practical grounds, to do anything that tended to separate research aimed at the applications of knowledge from the investigation of natural phenomena out of which this knowledge grows.

The remainder of this valuable survey into the role of a research council examines the Medical Research Council's relationship to Government. Its significance as a court of appeal in various aspects of medicine is but one tribute to its well-recognized independence.

\section{THE ELECTRICAL RESEARCH ASSOCIATION 1961}

$I^{\mathrm{T}}$ is significant that the opening paragraph of the report for 1961 of the Electrical Research Association * is headed "Electronics". The paragraph records a decision of the Council to expand the activities of the Association in the electronics field.

When the Association was formed in 1920 the part played by electronics in the electrical industry had scarcely become appreciable. Developments were just beginning whereby telecommunication in all its forms was to be revolutionized and, at a later stage, profound changes were to be effected in many branches of heavy electrical engineering.

* Electrical Research Association. 41st Annual Report for the year ended 31st December, 1961. Pp. 104. (E.R.A./T. 476.)
The research effort of the Association has been directed primarily towards problems in the heavy current field, but there has been a natural development of interest and activity in the many incidental applications of electronics. It is estimated that about 12 per cent of the Association's present research activities is of direct interest to the electronics branch of the industry and a further 6 per cent of indirect interest. Having regard to the central position which electronies is assuming in the electrical industry as a whole, it is now considered that the research programmes devoted to electronics and related subjects should be expanded until they reach half the total. The Council of the Association therefore proposes to examine the probable response from 